\title{
Epidemiology of gastrointestinal helminthiasis of small ruminants in selected sites of North Gondar zone, Northwest Ethiopia
}

\author{
Shimelis Dagnachew*, Asmare Amamute and Wudu Temesgen \\ University of Gondar, Faculty of Veterinary Medicine, \\ *Corresponding author: dagne2121@gmail.com
}

\begin{abstract}
A cross-sectional study was conducted to determine the prevalence and risk factors associated with small ruminant helminthiasis in north Gondar zone, northwest Ethiopia from November-January, 2008. A total of 558 small ruminants (458 sheep and 100 goats) were examined using standard parasitological procedure. The study revealed that the overall prevalence of helminthiasis was $47.67 \%$. The species level prevalence of helminthiasis was $46.07 \%$ and $55 \%$ in sheep and goats respectively. Strongyles were the most prevalent parasites encountered in the area followed by Fasciola. A statistically significant difference was found in prevalence between sheep and goat. Agroecology was found to be associated with prevalence rate and species of parasite found. Sex and age of the animals were shown to have association with prevalence but significant difference was not found. Therefore during the control and treatment of small ruminant helminthiasis agroecology, species, age and sex of the animals should be considered as potential risk factors for the occurrence of the disease in the study areas.
\end{abstract}

\section{Introduction}

Parasitism is of supreme importance in many agro-ecological zones and still a serious threat to the livestock economy worldwide (Vercruysse and Claerebout, 2001). Gastrointestinal helminth infections are recognized as a major constraint to livestock production throughout the tropics and elsewhere (Githiori et al., 2004). They cause lowered productivity (Perry and Randolph, 1999), mortality (Sykes, 1994), and high economic losses (Iqbal et al., 1993) affecting the income of small holder dairy farming communities. For successful formulation and implementation of an efficient and effective strategic helminth control regime, a periodic surveillance of the prevalence of gastrointestinal helminthiasis within given environment and associated risk factors that influence their transmission is required. Prevalence of gastrointestinal helminths has been reported ranging from 0.72 to $84.1 \%$ in domestic animals from various parts of the world (Bundy 
et al., 1983; Fikru Regassa et al., 2006; Khan et al., 2010). There are many associated risk factors influencing the prevalence of gastrointestinal helminths including age, sex, weather condition and husbandry or management practices (Miller et al., 1998; Khan et al., 2009). In Ethiopia, several studies have been conducted on ruminant helminthiasis of various regions reporting a prevalence range from 50.4-84.1\% (Fikru Regassa et al., 2006). However, these surveys were entirely restricted to the vicinity of veterinary institutions which may not be representative to the various geographical regions in Ethiopia which are unknown before as documentation of helminths of different animal species is concerned. Unfortunately, scanty report so far has been published on the prevalence of small ruminant helminthiasis in the present study areas (Yilma Jobre and Mesfin Ali, 2000).

In the diverse agro-climatic zones of Ethiopia, small ruminants are important source of income for rural communities and are one of the nation's major sources of foreign currency from exports. In Ethiopia there are about 45 millions of sheep and goats (CSA, 2008) providing more than $30 \%$ of domestic meat consumption. Small ruminants in north Gondar zone have a paramount importance for the livelihood of people and the majority of small ruminants are sheep in midland and highland areas conversely goats take the largest proportion in the lowland areas. However, diseases often prevent them from attaining optimum productivity. Therefore, the current study was conducted to generate baseline data on the prevalence of gastrointestinal parasites in small ruminants of north Gondar zone, Northwest Ethiopia. An attempt was made to identify risk factors in relation to parasitism.

\section{Materials and Methods}

\section{Study Area}

The study was undertaken from November-December 2008 in 4 selected districts of North Gondar zone; Northwest Ethiopia comprises 3 agro-ecologies (Dabat from highland, Gondar Zuria and Dembia from midland and Chillga from lowland) as shown in Figure 1. The altitude range of the study areas were less than 1500 m.a.s.l. (lowland), 1500-2000 m.a.s.l. (midland) and 2500-3200 m.a.s.l. (highland) with a mean temperature of $26.4^{\circ} \mathrm{C}, 17.5^{\circ} \mathrm{C}$ and $12.5^{\circ} \mathrm{C}$ respectively. The area is located at latitude $12.4^{\circ} \mathrm{N}$ and longitude of $27.25^{\circ} \mathrm{E}$. 


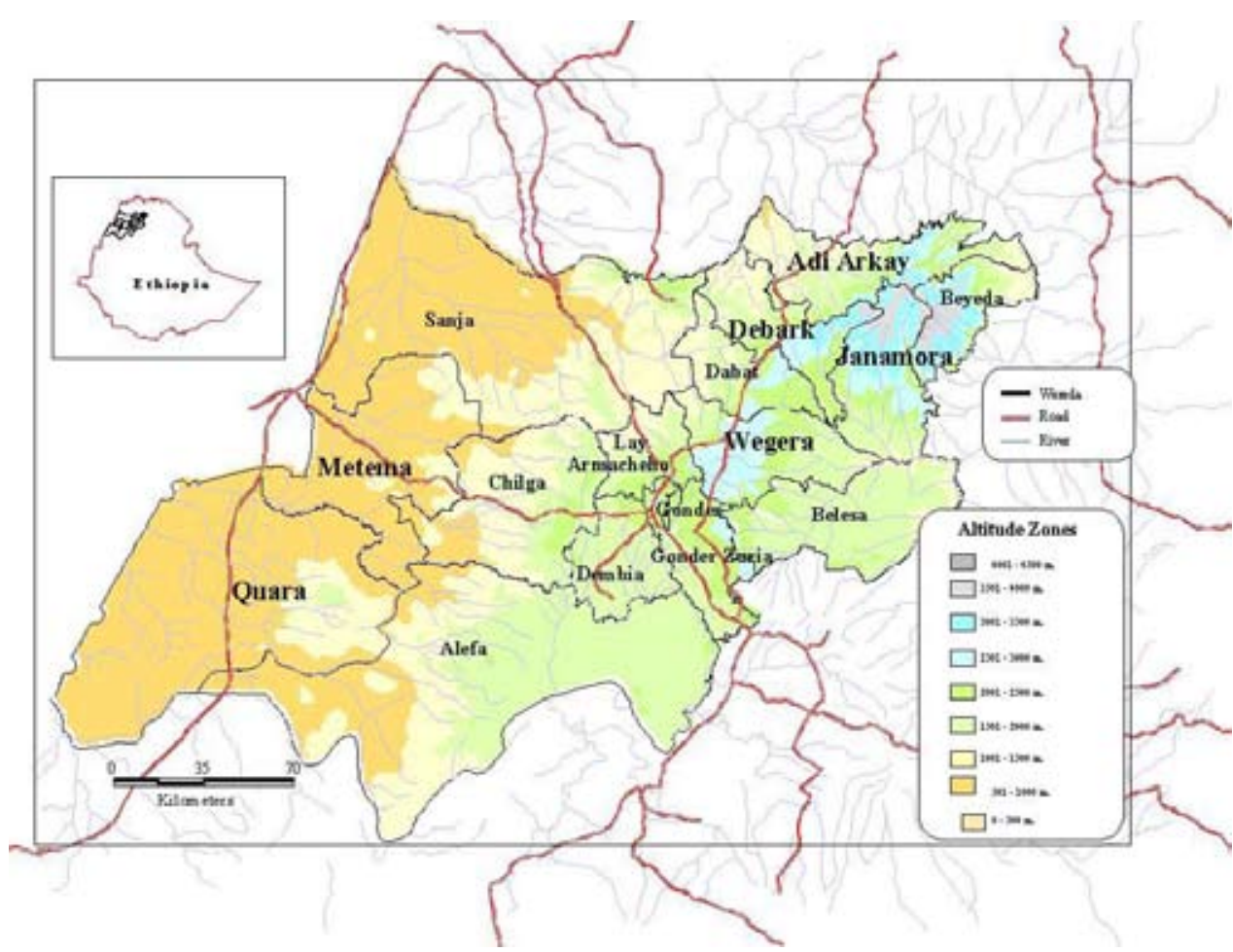

Figure 1. Map of the study area (Dabat, Gondar Zuria, Dembia and Chillga districts) of North Gondar zone (World Food Program Vulnerability Analysis and Mapping Unit, Ethiopia, July 1998).

\section{Study Design}

\section{Questionnaire survey}

Questionnaire survey was done with a well-structured prepared questionnaire format which was refined through informal and formal surveys (Thrusfield, 2007). A total of 60 farmers living in the study areas were interviewed and the main points included in the questionnaire were farming systems (type of feeding i.e., grazing or stall feeding, source of drinking water i.e. ponds, rivers/canals or fresh tap water). Furthermore, constraints of small ruminant production and local and conventional techniques to solve major problems and the amount of costs incurred for treating their sheep and goat were included. 


\section{Prevalence study}

A cross-sectional study using multi-stage random sampling procedure was used to select peasant associations (PAs) and the animals for the determination of prevalence of helminth parasites in the study areas. From each district PAs were randomly selected and fecal samples were collected directly from the rectum of 558 animals (458 sheep and 100 goats). During sampling age, sex and clinical examination records were made. Age groups were categorized in to young ( $<6$ months) and adult ( $>6$ months) based on farmers response and observations made during sampling. The collected feces were preserved in $10 \%$ formalin and brought to Parasitology laboratory in the Faculty of Veterinary Medicine, University of Gondar for coprological examination. Parasitological examination was done by sedimentation and flotation techniques following the standard procedures (Hansen, 1994; Shah-Fischer, 1989). The eggs of different parasite species were identified using keys given by Soulsby (1982).

\section{Data Analysis}

The descriptive data obtained were analyzed through multiple logistic regressions in order to measure the significance of possible associated determinants (species, age, sex, and agroecology) on the prevalence of gastrointestinal helminths (Thrusfield, 2007). SPSS version 15.1 (SPSS, Inc. Chicago, Ill) was used for the analysis of data. Percentages (\%) to measure prevalence and logistic regression and chi-square to measure odds ratio and association between prevalence of the parasite and species of the animals, age, sex and agroecology were the statistical tools applied. In all the analyses, confidence level was held at $95 \%$ and $\mathrm{P}<0.05$ was set for significance.

\section{Results}

\section{Questionnaire survey}

A total of 60 farmers were interviewed from 11 PAs on major constraints of small ruminant production. In the high land areas of livestock species sheep stand first for the livelihood of the family as explained by $60 \%$ of the respondents followed by cattle and equines indicated by $25 \%$ and $15 \%$ of the respondents respectively. The interviewed farmers also indicated that the shortage of grazing land and watering points make the flocks of different localities graze together which affects their productivity. In the lowland areas cattle is the dominant domestic animal as explained by $75 \%$ of the respondents and followed by goats. The interviewed peoples mentioned that there was no 
shortage of grazing land, however, the uncontrolled animal movements in the areas exacerbate the transmission of contagious diseases. In both agroecology $70 \%$ of the respondents indicated that mortality and morbidity of sheep and goat is commonly observed at the beginning of the rainy season (55\%), in the rainy season (35\%) and at the mid of dry period (10\%). Consequently, Berer scientifically called as fasciolosis and respiratory diseases are the major constraint of sheep health in the high land areas while infectious diseases and skin diseases are major challenge in the lowland areas as explained by $80 \%$ and $65 \%$ of the respondents respectively. Similarly respiratory and enteric infections are equally important in the midland areas responded by $70 \%$ of the interviewed people. More than $65 \%$ of the respondents mentioned that one of the strategies used for any abnormalities of sheep and goat is treatment with anthelmintics primarily from private and illegal shopping. More than $90 \%$ of the respondent explained that 4 to six times treatment were given against helminthiasis which costs about 50-60 birr per animal per year. The reasons indicated by the intervied people for the frequent applications of anthelmintics were due to animals could not effectively recover from suspected infection.

\section{Overall prevalence}

Out of 558 sheep and goats examined, $47.67 \%(\mathrm{n}=266)$ were found to harbor one or more parasite species.

\section{Prevalence of helminth parasites by host and parasite species}

The prevalence of gastrointestinal helminthes was higher in goats than sheep but not significantly different as shown in Table 1. The prevalence of Fasciola and Monezia were significantly higher in sheep compared to goats $(\mathrm{P}<0.01)$. The gastrointestinal parasites found in the small ruminant population of the study area were Fasciola hepatica; Strongyle species. (Haemonchus, Trichostrongylus, Ostertagia and Cooperia), Trichuris spp., Monezia spp. and Paraphistomum spp.. The dominant helminth parasite species found during the study period were Strongyle (37.63\%) followed by Fasciola (6.99\%) and the lowest was Paraphistomum (0.72\%). 
Table 1: Prevalence of small ruminant helminthiasis in sheep and goats in selected districts of North Gondar zone during the study period

\begin{tabular}{|c|c|c|c|c|c|c|c|}
\hline \multirow[t]{2}{*}{ Species } & \multirow{2}{*}{$\begin{array}{l}\text { No. } \\
\text { exam. }\end{array}$} & \multirow{2}{*}{$\begin{array}{l}\text { No. } \\
\text { positive }\end{array}$} & \multicolumn{5}{|c|}{ Types of parasite indentified } \\
\hline & & & Fasciola & Strongyle & Trichuris & Monezia & Paraphi. \\
\hline Sheep & 458 & $211(46.07 \%)$ & $39(8.52 \%)^{*}$ & $156(34.06 \%)$ & $22(4.8 \%)$ & $18(3.93 \%)^{*}$ & $4(0.87 \%)$ \\
\hline Goats & 100 & $55(55 \%)$ & 0 & $54(54 \%)$ & $3(3 \%)$ & 0 & 0 \\
\hline Total & 558 & $266(47.67 \%)$ & $39(6.99 \%)$ & $210(37.63 \%)$ & $25(4.48 \%)$ & $18(3.23 \%)$ & $4(0.725)$ \\
\hline
\end{tabular}

*: significant difference $(\mathrm{P}<0.05)$

\section{Prevalence of helminth parasites by age of animals}

Younger animals tend to be more susceptible to helminthiasis as compared to adults. However, these differences were not significant $(\mathrm{P}>0.05)$. In addition; the prevalence of Trichuris infestation was significantly higher in young animals compared to adults in both sheep and goats $(\mathrm{P}<0.05)$.

Table 2: Prevalence of small ruminant helminthiasis by age category in selected districts of North Gondar zone during the study period

\begin{tabular}{lccccccc}
\hline Age & No. & No. & \multicolumn{5}{c}{ Types of parasite in genus } \\
\cline { 4 - 8 } & exam. & positive & Fasciola & Strongyle & Trichuris & Monezia & Paraphi. \\
\hline Young & 145 & $72(49.65 \%)$ & $10(6.89 \%)$ & $52(35.86 \%)$ & $12(8.27 \%)^{*}$ & $7(4.83 \%)$ & $3(2.07 \%)$ \\
Adult & 443 & $194(43.79 \%)$ & $29(6.55 \%)$ & $158(35.66 \%)$ & $13(2.93 \%)^{*}$ & $11(2.48 \%)$ & $1(0.23 \%)$ \\
Total & 558 & $266(47.67 \%)$ & $39(6.99 \%)$ & $210(37.63 \%)$ & $25(4.48 \%)$ & $18(3.23 \%)$ & $4(072 \%)$ \\
\hline
\end{tabular}

*: significant difference $(\mathrm{P}<0.05)$

\section{Prevalence of helminth parasites in male and female small ruminants}

Relatively higher prevalence of helminthiasis was observed in female animals (48.8\%) compared to male $(42.42 \%)$ but the difference was not significant $(\mathrm{P}>0.05)$ as indicated in Table 3.The finding was also similar in sheep and goats irrespective of their species.

Table 3: Prevalence of small ruminant helminthiasis in sex category in selected districts of North Gondar zone during the study period

\begin{tabular}{|c|c|c|c|c|c|c|c|}
\hline \multirow[t]{2}{*}{ Sex } & \multirow{2}{*}{$\begin{array}{l}\text { No } \\
\text { exam. }\end{array}$} & \multirow{2}{*}{$\begin{array}{l}\text { No. } \\
\text { positive }\end{array}$} & \multicolumn{5}{|c|}{ Types of parasite in genus } \\
\hline & & & Fasciola & Strongyle & Trichuris & Monezia & Paraphi. \\
\hline Male & 99 & $42(42.42 \%)$ & $7\left(7.07^{\circ}\right.$ & & $4(4.04$ & & \\
\hline Female & 459 & $224(48.80 \%)$ & $32(6.97 \%)$ & 180(39.21\%) & $21(4.57 \%)$ & $14(3.05 \%)$ & $2(0.45 \%)$ \\
\hline Total & 558 & $266(46.67 \%)$ & $39(6.99 \%)$ & $210(37.63 \%)$ & $25(4.48 \%)$ & $18(3.23 \%)$ & $4(0.72 \%)$ \\
\hline
\end{tabular}




\section{Prevalence of helminth parasites by agroecology}

Among the three agroecological zones; significant difference $(\mathrm{P}<0.05)$ was found in the distribution of gastrointestinal helminth infections of the examined animals between highland and lowland areas. The highest prevalence of helminthiasis was found in Gondar Zuria followed by Chillga. There was statistically significant difference in the species prevalence of helminthiasis with the highest being in Chillga (lowland) for strongyle infection (55.45\%) and the lowest was in Dabat (highland) (22.52\%). Infection with Fasciola was significantly higher $(\mathrm{P}<0.05)$ in Dabat $(15.48 \%)$ district compared to other districts in midland and lowland agroecology as shown (Table 4).

Table 4: Prevalence of small ruminant helminthiasis in selected districts of north Gondar Zone

\begin{tabular}{llllllll}
\hline $\begin{array}{l}\text { District } \\
\text { (agroecology) }\end{array}$ & $\begin{array}{l}\text { No } \\
\text { exam. }\end{array}$ & $\begin{array}{l}\text { No } \\
\text { positive }\end{array}$ & \multicolumn{2}{l}{ Types of parasite in genus level } \\
\cline { 5 - 8 } & Fasciola & Strongyle & Trichuris & Monezia & Paraphi. \\
\hline Gondar Zuria & 66 & $40(60.6 \%)$ & 0 & $28(42.42 \%)$ & $2(3.03 \%)$ & $14(21.21 \%)$ & 0 \\
Dembia & 139 & $71(51.08)$ & 0 & $69(49.64 \%)$ & $3(2.16 \%)$ & $3(2.16 \%)$ & 0 \\
Dabat & 252 & $101(40.08)$ & $39(15.48 \%)^{*}$ & $57(22.62 \%)^{*}$ & $16(6.34 \%)$ & $1(0.39 \%)$ & $4(1.59 \%)$ \\
Chillga & 101 & $54(53.47 \%)$ & 0 & $56(55.45 \%)^{*}$ & $4(3.96 \%)$ & 0 & 0 \\
Total & 558 & $266(47.67 \%)$ & $39(6.99 \%)$ & $210(37.63 \%)$ & $25(4.48 \%)$ & $18(3.23 \%)$ & $4(0.72 \%)$ \\
\hline
\end{tabular}

*: significant difference $(\mathrm{P}<0.05)$

The infection of helminthiasis include more than one types of parasite was found in $5.37 \%$ of the examined animals. Of this the infection of Strongyle and Trichuris seize the highest concurrent infection followed by Fasciola and Strongyle.

\section{Discussion}

The investigation of different putative factors of helminth infection showed that agroecology was found to be important in determining levels of infection for species of parasite in the study areas. Gastrointestinal helminthiasis was found prevalent throughout the year but with variable levels of infection in the different host categories and climatic environment. The probable reasons of decreased infection of gastrointestinal helminths in the present study may be due to the unfavorable environmental factors for the development and growth of most helminth species (Andrews 1999; Lima et al., 1998). Most of the helminth species are susceptible to desiccation in dry climatic conditions that results from the high temperature at which even eggs fail to develop into L3 (Banks et al., 1990; Tembely 1998; Waruiru et al., 1998). This may be the 
reason for lower infection compared to reports in other studies which were done in different seasons of the year. The present findings are in agreement with studies in western Ethiopia indicating positive association of climatic factors with prevalence of gastrointestinal helminths of various host species (Fikru Regassa et al., 2006). The helminth parasites identified in two animal species in this study (Fasciola hepatica, Strongyle spp., Trichuris spp., Moniezia spp. and Paraphistomum) has also been reported previously in other localities (Fikru Regassa et al., 2006). In previous reports; the most frequently occurring gastrointestinal helminth species were $T$. vitulorum and $H$. contortus in large and small ruminants, respectively. However, in the present study $F$. hepatica was restricted in sheep in Dabat district with highland agroecology where as Stongyle species was the most prevalent and distributed in all agroecological zones. This difference may be attributed to variations in climate and farming practices of various districts of North Gondar zone, especially the presence of marshy areas, favorable habitat of the intermediate host of Fasciola (Spithill et al., 1999) in Dabat as a water source for the grazing animals. This is further supported by the highest rate of infection in animals using ponds as a water source followed in order by those using rivers and piped sources.

The prevalence of helminthiasis both in sheep and goat is comparable but relatively higher in goats which varied from other reports (Nganga et al., 2004; Taylor 1985). The reason that goats are kept on semi-intensive grazing system (Nganga et al., 2004) and prefer to browse shrubs (Taylor, 1985) which might reduce the infection rate was not found in the present study. This variation might be associated to the practice of grazing sheep and goat together in the same area so that goats may acquire more susceptibility for the same species of parasite infection. Immunological response of goats for helminth infection is limited compared to sheep (Urquhart et al., 1996). The findings of our work is in a harmony to different researchers (Fikru Regassa et al., 2006; Keyyu et al., 2006; Raza et al., 2007) who have found a direct influence of grazing characteristics on the prevalence of most of gastrointestinal helminths.

Females animals showed were affected higher infection rates than males despite similar husbandry practice. This finding supports with the general understanding of helminth infections that female animals are more susceptible to helminthiasis. It is assumed that sex is a determinant factor influencing prevalence of parasitism (Maqsood et al., 1996; Valcárcel and García, 1999) and females are more prone to parasitism during pregnancy and peri-parturient period due to stress and decreased immune status (Urquhart et al., 1996). In the present study lower prevalence in adults may be due to the immunological 
maturity as the animals get older and the development of acquired resistance due to repeated exposure. The hypothesis that older animals can acquire immunity against gastrointestinal parasites has been supported experimentally by different studies (Gamble and Zajac 1992; Knox, 2000). Similarly, a number of authors have demonstrated an increased prevalence in young age (Gupta et al., 1976; Raza et al., 2007).

\section{Conclusion}

Small ruminant helminthiasis is found to be an important problem in the study areas. Therefore during the control and treatment of small ruminant helminthiasis species, age and agroecology should be considered as potential risk factors for the occurrence of the disease. Further studies on the economic importance of helminthiasis and drug resistance patterns of anthelmintics should be conducted for the holistic implementation of helminthiasis control.

\section{Acknowledgments}

The author would like to thank University of Gondar, research and publication office for the financial support. The contribution of district veterinary professionals by facilitating the field work activities and the cooperation of farmers for interview deserve deep appreciation.

\section{References}

Andrews, S. J., 1999. The life cycle of Fasciola hepatica. In: Dalton JP (ed) Fasciolosis. $\mathrm{CAB}$, Wallingford, pp 1-29.

Banks, D. J. D., Singh, R., Barger, I. A., Pratap, B. and Le Jambre, L. F., 1990. Development and survival of infected larvae of Haemonchus contortus and Trichostrongylus colubriformis on pastures in a tropical environment. Int. J. Parasitol., 20(2):155-60.

Bundy, D. A. P., Arambulo, P. V. and Grey, C. L., 1983. Fascioliasis in Jamaica: epidemiologic and economic aspects of a snail-borne parasitic zoonosis. Bull Pan Am Hlth Org., 17:243-258

CSA, 2008. Central statistics agency, Addis Ababa, Ethiopia.

Gamble, H. R. and Zajac, A. M., 1992. Resistance of St. Croix lambs to haemonchus contortus in experimentally and naturally acquired infections. Vet Parasitol, 41:211-225. 
Githiori, J. B., Hogland, J., Waller, P. J. and Baker, R. L., 2004. Evaluation of anthelmintic properties of some plants used as livestock dewormers against Haemonchus contortus infection in sheep. Parasitol.,129:245-53.

Gupta, G. C., Joshi, B. P. and Rai, P., 1976. Some aspects of biochemical studies in calf diseases ascaridiasis and scour. Indian Vet J., 53:436-441.

Hansen, J. and Perry, B., 1994. The Epidemiology, Diagnosis and Control of Helminth Parasites of Ruminants. $2^{\text {nd }}$ edition. Nairobi, Kenya; ILRAD.

Iqbal, Z., Akhtar, M., Khan, M. N.and Riaz, M., 1993. Prevalence and economic significance of haemonchosis in sheep and goats slaughtered at Faisalabad abattoir. Pakistan J Agric Sci., 30:51-53

Jobre, Y. and Ali, M., 2000. Dry season bovine fasciolosis in northwestern part of Ethiopia. Revue Méd. Vét., 151(6), 493-500.

Keyyu, J.D., Kassuku, A.A., Msalilwa, L.P., Monrad, J. and Kyvsgaard, N.C., 2006. Cross-sectional prevalence of helminth infections in cattle on traditional, smallscale and large-scale dairy farms in Iringa district, Tanzania. Vet Res Commun., 30:45-55

Khan, M.N., Sajid, M.S., Iqbal, Z. and Hussain, A., 2010. Gastrointestinal helminthiasis: prevalence and associated determinants in domestic ruminants of district Toba Tek Singh, Punjab, Pakistan. Parasitol. Res., 107:787-794.

Khan, M.K., Sajid, M.S., Khan, M.N., Iqbal, Z. and Iqbal, M.U., 2009. Bovine fasciolosis: prevalence, effects of treatment on productivity andcost benefit analysis in five districts of Punjab, Pakistan. Res Vet Sci., 87:70-75.

Knox, D.P., 2000. Development of vaccines against gastrointestinal nematodes. Parasitol 120:S43-S61

Lima, W.S. 1998. Seasonal infection pattern of gastrointestinal nematodes of beef cattle in Minas Gerais State-Brazil. Vet. Parasitol., 74:203-214.

Maqsood, M., Iqbal, Z., Chaudhry, A.H. 1996. Prevalence and intensity of haemonchosis with reference to breed, sex and age of sheep and goats. Pakistan Vet J., 16:4143.

Miller, J.E., Bahirathan, M., Lemarie, S.L., Hembry, F.G., Kearney, M.T. and Barras, S.R., 1998. Epidemiology of gastrointestinal nematode parasitism in suffolk and 
gulf COAST native sheep with special emphasis on relative susceptibility to Haemonchus contortus infection. Vet. Parasitol., 74:55-74

Nganga, C.J., Maingi, N. and Munyua, W.K. and Kanyari, P.W., 2004. Epidemiology of gastrointestinal helminths infection in Dorper sheep in semi-arid area of Kenya. Ondestepool J Vet Res. 71(3):219-226.

Perry, B.D. and Randolph, T.F., 1999. Improving the assessment of the economic impact of parasitic diseases and of their control in production animals. Vet. Parasitol., 84:145-168

Raza, M.A., Iqbal, Z., Jabbar, A. and Yaseen, M. 2007. Point prevalence of gastrointestinal helminthiasis in ruminants in southern Punjab.Pakistan $J$ Helminthol., 81:323328

Regassa, F., Teshale, S., Reta, D. and Yosef, K., 2006. Epidemiology of gastrointestinal parasites of ruminants in Western Oromia, Ethiopia. Intl J Appl Res Vet Med., 4(1):51-57

Shah-Fischer, M. and Say, R., 1989. Manual of Tropical Veterinary Parasitology. CAB International; The Technical Center for Agricultural and Rural Cooperation (CTA).

Soulsby, E.J.L.,1982. Helminths, arthropods and protozoa of domesticated animals, 7th edn. Tindall, London, p.809

Spithill, T.W., Smooker, P.M. and Copeman, D.B., 1999. Fasciola gigantica: epidemiology, control, immunology and molecular biology. In:Dalton JP (ed) Fasciolosis. CAB, Wallingford, pp 465-525

Sykes, A.R., 1994. Parasitism and production in farm ruminants. Anim Prod. 59:155172

Taylor, C.A., 1985. Multispecies Grazing Research Overview (Texas).In: Proceedings of a conference on multispecies grazing. June 25-28, 1985, Winrock International, Morrilton, AR pp, 65-68.

Tembely, S., Lahlou-Kassi, K.and Rege, J.E., 1998. Breed and season effects on the peri-parturient rise in nematode egg output in indigenous ewes in a cool tropical environment. Vet Parasitol. 77(2-3):123-132.

Thrusfield, M., 2007. Veterinary epidemiology. Blackwell, USA. 
Urquhart, G.M., Armour, J., Duncan, J.L., Dunn, A.M. and Jennings, F.W., 1996. Veterinary Parasitology. $2^{\text {nd }}$ edition. Blackwell Science.

Valcárcel, F. and García, R. C., 1999. Prevalence and seasonal pattern of caprine trichostrongyles in a dry area of central Spain. $J$ Vet Med., 6:673-680.

Vercruysse, J. and Claerebout, E., 2001. Treatment vs. non-treatment of helminth infections in cattle: defining the thresholds. Vet Parasitol., 98:195-214.

Waruiru, R.M., Mutune, M.N. and Otieno, R.O., 2005. Gastrointestinal parasite infections of sheep and goats in a semi-arid area of Machakos District, Kenya. Bull Anim Health Prod Afr. 53(1):25-34.

World Food Program Vulnerability Analysis and Mapping Unit, Ethiopia, July 1998. UN capital development fund, Ethiopia, Fund for community and local development. 